\title{
Relative tolerance of photosystem II in spike, leaf, and stem of bread and durum wheat under desiccation
}

\author{
J. RANE ${ }^{*+}$, D. SHARMA*, S. EKATPURE*, L. AHER ${ }^{*}$, M. KUMAR*, S.V.S. PRASAD ${ }^{* *}$, \\ A.N. NANKAR ${ }^{* * *}$, and N.P. SINGH \\ Indian Council of Agricultural Research-National Institute of Abiotic Stress Management (ICAR-NIASM), \\ Baramati, 413115 Maharashtra, India* \\ Regional Station, Indian Council of Agricultural Research-Indian Agricultural Research Institute (ICAR-IARI), \\ 452001 Indore, Madhya Pradesh, India** \\ Center of Plant Systems Biology and Biotechnology (CPSBB), 4000 Plovdiv, Bulgaria ${ }^{* * *}$
}

\begin{abstract}
In dryland regions, soil moisture stress often leads to desiccation and causes injury to photosynthetic machinery. Recently, chlorophyll fluorescence (ChlF)-based assessment of photosynthetic efficiency under drought stress is gaining attention due to advances in instrument development and methodology optimisation. Our study was designed to explore the use of spike photosynthetic efficiency as a trait to differentiate drought responses in wheat. Bread and durum wheat were assessed for spike, stem, and leaf tissue photosynthetic efficiency in response to progressive desiccation using ChlF imaging. Results showed that durum wheat had higher quantum efficiency and lower photoinhibition of PSII relative to bread wheat across spike, stem, and leaf. Rate of decline in maximum photochemical efficiency of PSII with increased desiccation was seen higher in bread wheat spikes as compared to durum wheat. Our investigation clearly demonstrated that ChlF imaging could be effectively deployed as phenotyping tool to differentiate wheat genotypes for their photosynthetic performance under desiccation.
\end{abstract}

Additional key words: desiccation tolerance; fluorescence imaging; genetic variation; high throughput; plant phenotyping.

\section{Introduction}

Soil moisture stress is one of the major abiotic stress constraints. Desiccation of photosynthetic plant parts due to prolonged soil moisture deficit limits wheat productivity in dry and hot agro-ecosystems (Reynolds et al. 2016). Frequency of drought stress is likely to increase in more geographical regions with constant unpredictable changes in climatic events (Hochman et al. 2009). Hence genetic variation in sensitivity of plant physiological processes including photosynthesis to drought is critical to develop climate-resilient crops. Such scientific leads can be translated into physiological traits for indirect selection that can assist to increase wheat yield potential under abiotic stress (Terrile et al. 2017). Successful introgression of identified novel traits could be economic and cost effective approach to develop abiotic stress-tolerant germplasm (Varshney et al. 2018).

Two wheat species, bread wheat (Triticum aestivum L.) and durum wheat (Triticum durum Desf.) are cultivated as major staple food crops. While bread wheat is grown extensively around the world (Al-Ghzawi et al. 2018), durum wheat is still limited to semiarid tropics (Vaghar and Ehsanzadeh 2018). These two species differ substantially in their sensitivity to desiccation, though genetic resources of both the species are traced back to wheat originated from Fertile Crescent region of Middle East characterised by relatively harsher environmental conditions including drought. Usually durum wheat is considered to be more desiccation tolerant than bread wheat (López-Castañeda and Richards 1994, Trethowan et al. 2001, Monneveux et al. 2012, Marti and Slafer 2014), although some exceptions have been reported in the past (Josephides 1992, Palumbo and Boggini 1994, Zubaidi et al. 1999). Moreover, only few comparative studies have been carried out to investigate the effect of desiccation on photosynthetic efficiency in these species (Aggarwal et al. 1986, Josephides 1992, Palumbo and Boggini 1994, Zubaidi et al. 1999, Calderini et al. 2006). However, none of these conclusions have been supported unambiguously and

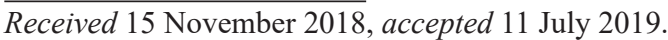

${ }^{+}$Corresponding author; phone: +91-9404684508, fax: +91-02112254056, e-mail: Jagadish.rane@icar.gov.in, jagrane@hotmail.com Abbreviations: ChlF - chlorophyll fluorescence; $\mathrm{F}_{0}$ - initial fluorescence; $\mathrm{F}_{\mathrm{m}}-$ maximum fluorescence; $\mathrm{F}_{\mathrm{v}}-$ variable fluorescence; $\mathrm{F}_{\mathrm{v}} / \mathrm{F}_{\mathrm{m}}$ - maximum photochemical efficiency of PSII.

Acknowledgements: We thank to Department of Biotechnology, India, for financial assistance to this work (grant for the BBSRC-DBT funded project BT/IN/Indo-UK/CGAT/17/PS/2014-15) and ICAR-NICRA (project ID OXX01737). We also thank to ICAR-NIASM for creating $\mathrm{ChlF}$ fluorescence imaging facility at the institute. We also thank to unknown reviewers who provided valuable suggestions to improve the manuscript.
} 
findings from these studies are inconsistent and are still largely debated.

Photosynthesis is a vital process that maintains overall crop growth and development. It is widely known that photosynthetic organs that drive the photosynthesis in higher plants are most sensitive to desiccation (Falk et al. 1996). Previous investigation has shown that PSII is the most sensitive to desiccation and its sensitivity could be strongly associated with the desiccation severity. Giardi et al. (1996) and Skotnica et al. (2000) reported that desiccation causes severe damage to PSII, while other investigations have suggested that PSII is quite resistant, either being unaffected or affected only under severe desiccation in light-adapted leaves (Lu and Zhang 1998). The inconsistency among these studies might be partially due to different methods and stress duration. Nonetheless, it is evident that these techniques besides primary scientific leads need to be translated into tools that efficiently differentiate genotypes differing in plant photosynthetic performance under desiccation. These tasks can be accomplished efficiently with recent advances in instrumentation that allow rapid measurements of photosystem health.

Chlorophyll fluorescence (ChlF) analysis is a noninvasive technique that investigates plant photosynthetic performance and is efficient in dealing with a large number of plants (Guidi and Calatayud 2014). The ChlF is a complex reflection of primary reactions occurring during photosynthesis and indicates the status of PSII that drives photosynthesis (Stirbet et al. 2018). In cereals, such as wheat, fluorescence transients of dark-adapted leaves measured by ChlF analyzer can provide useful information related to desiccation response of photosynthetic apparatus (Maxwell and Johnson 2000, Sayed 2003, Stirbet et al. 2018). Applicability of ChlF parameters for rapid screening of tolerance to unfavourable environmental conditions has been discussed previously (Lichtenthaler et al. 2005, Živčák et al. 2013, Lazár 2015, Goltsev et al. 2016, Kalaji et al. 2017, Osipova et al. 2019) and many of these studies on ChlF parameters were measured on plant leaves.

Soil moisture deficit during grain filling often limits the crop productivity. Under such situation, grainfilling process is largely sustained by photosynthesis in upper parts of wheat plants including flag leaf and spike (Tambussi et al. 2005). Researchers have primarily focused on flag leaf photosynthesis since it is a key plant organ that supplies majority of assimilates to developing grains (Evans et al. 1975). However, several studies reveal that wheat spike is an important source of photosynthetic carbon assimilation during grain filling, particularly when plants are water-stressed (Abbad et al. 2004, Maydup et al. 2012, Jia et al. 2015). Now it is increasingly accepted that spike photosynthesis is a major contributor to the final grain yield of wheat (Simmons 1987, Araus et al. 1993, Tambussi et al. 2007). Reynolds et al. (2005) proposed that elevated photosynthesis in wheat spikes is an important trait for drought tolerance. In present study, we aimed to focus on wheat spike and attempted to employ ChlF imaging tools to compare durum and bread wheat. Our hypothesis is that the spike PSII tolerance to desiccation might be one of the reasons for better adaptability of durum wheat as compared to bread wheat.

\section{Materials and methods}

Plant material and experimental design: Two wheat cultivars, one of bread wheat (HI 1531) and one of durum wheat (HI 8498), were used in this study. Seeds were obtained from Regional Station of Indian Agricultural Research Institute, Indore, which leads the efforts to develop wheat cultivars for hot and dry region. Both cultivars were sown in plots with six rows of $2.0-\mathrm{m}$ length with $10 \mathrm{~cm}$ within and $25 \mathrm{~cm}$ between row spacing at National Institute of Abiotic Stress Management (NIASM), Baramati, Maharashtra, during the first week of December 2015. The experimental field was managed using common wheat cultivation practices. $\mathrm{N}, \mathrm{P}$, and $\mathrm{K}$ were applied at the rate of 60,60 , and $40 \mathrm{~kg} \mathrm{ha}^{-1}$, respectively, during sowing, and additional $\mathrm{N}$ application was given at crown root initiation. The crop was irrigated four times at an interval of 20 to $25 \mathrm{~d}$, while the crop duration was around $110 \mathrm{~d}$. The experimental field was kept free of weeds throughout the experiments and no disease or pest incidences were reported, hence no disease control measures were taken.

ChF measurements: Three weeks after anthesis (Zadoks scale 75, medium milk: grain content milky, grains reached final size, still green, Zadoks et al. 1974), five main shoots containing flag leaf and spikes were harvested using a pair of scissors. To avoid air gaps, a part of stem immediately below the spike was cut within the test tube containing water to prevent any damage to spike or flag leaf. Initially, eight to ten spikes from each genotype were harvested but only five undamaged and uniform samples were retained for ChlF measurements. Sampling was carried out at around 09:00 $\mathrm{h}$ and samples were then shifted to a dark room and were adapted and stabilized for the next $3 \mathrm{~h}$ under dark. Dark-acclimatized and stabilized samples were taken out and first measurement was recorded on each sample. After measurements, the samples were kept in empty test tubes to impose desiccation at room temperature $\left(28^{\circ} \mathrm{C}\right)$ and at PAR of $150 \mu \mathrm{mol}$ (photon) $\mathrm{m}^{-2} \mathrm{~s}^{-1}$ until all samples were analysed. It took approximately 25 to $35 \mathrm{~min}$ for each set of measurements to be completed. Subsequently, lights in the ChlF imaging chamber were turned off before the next measurement. Similar samples were used to measure ChlF for additional four times at an interval of $1 \mathrm{~h}$ during desiccation. Thus before every measurement, the samples were kept in dark for at least $25 \mathrm{~min}$ and temperature in imaging chamber was set around $28^{\circ} \mathrm{C}$. ChlF was measured in spike, leaf, and stem at an hourly basis with an imaging fluorometer (Handy FluorCam, P.S.I., Brno, Czech Republic) as described in Nedbal et al. (2000). Fluorescence was detected by a high-sensitivity charge coupled device camera and it was driven by FluorCam software package (FluorCam 7). First, images of dark-adapted fluorescence level $\left(\mathrm{F}_{0}\right)$ were determined using nonactinic measuring flashes provided by super-bright light emitting diodes (LEDs). Next, an 800 -ms duration pulse of saturating light radiation 
[2,500 $\mu \mathrm{mol}$ (photon) $\left.\mathrm{m}^{-2} \mathrm{~s}^{-1}\right]$ generated by a halogen lamp was given to measure maximum fluorescence level $\left(\mathrm{F}_{\mathrm{m}}\right)$. Maximal photochemical efficiency of PSII $\left(\mathrm{F}_{\mathrm{v}} / \mathrm{F}_{\mathrm{m}}\right)$ was calculated as $\left(\mathrm{F}_{\mathrm{m}}-\mathrm{F}_{0}\right) / \mathrm{F}_{\mathrm{m}}$. Pixel value images of $\mathrm{F}_{\mathrm{v}} / \mathrm{F}_{\mathrm{m}}$ were displayed as a false colour code ranging from red $(0.35)$ to green and yellow to blue $(0.85)$. Variable fluorescence $\left(F_{v}\right)$ is the difference between $F_{m}$ and $F_{0}$. The $F_{v}$ and $F_{m}$ values were further utilized to calculate $F_{v} / F_{m}$, which indicates the quantum efficiency of PSII.

Moisture content: To monitor moisture content loss, spike fresh mass (excluding stem and leaf) was recorded by using precision balance immediately after Chl fluorescence images were acquired for analysis and thus there were five observations for each spike at an interval of $1 \mathrm{~h}$. After each measurement, each spike was placed back in a labelled and dry test tube. After final measurement, spikes were kept in oven at $70^{\circ} \mathrm{C}$ for $8 \mathrm{~h}$ to reach the final dry mass. Moisture content as per cent of fresh mass at any given point was calculated using following equation: moisture content $=$ (fresh mass - final dry mass) $\times 100 /$ fresh mass.

Statistical analysis: The ChlF data for tissue type and time (hours of treatment) were analysed using repeated measured analysis of variance $(A N O V A)$. Tissues were between-subject factors and time was repeated measure factor, i.e., within-subject factor. Mauchly's test was performed to check the validity of sphericity assumption. Tukey's pairwise comparison was used to determine differences between treatment effect in each tissue and combination of tissue pairs at each time point. ChlF after $3 \mathrm{~h}$, i.e., at the start of desiccation, was taken as reference. All statistical analyses were performed in SAS v. 9.3 (SAS Institute Inc., Cary, NC).

\section{Results}

Moisture content of plant tissues during desiccation: Moisture content was reported only in spikes and was observed to differ significantly between both wheat species as well as between different time points (hour of desiccation). At the start of desiccation, the moisture content was slightly higher in bread wheat and a progressive decline in tissue moisture content was observed during desiccation period and a similar trend was observed between bread and durum wheat. In bread wheat, moisture decreased from 74 to $48 \%$, while in durum wheat, moisture decreased from 66 to $44 \%$ (Fig. 1S, supplement). Thus, the tissue moisture content of spike was lesser in durum relative to bread wheat.

ChIF in photosynthetic parts: Mauchly's tests revealed that sphericity assumption was violated for all ChlF variables during desiccation, since variances and covariances were significantly different between repeated samples. Hence, $P$-values adjusted with G-G correction factor were used for analysis (Table 1). Main source of variation considered for analysis were plant parts, duration of desiccation (annotated at time), and interaction between these two factors. Main effects and interaction effects were presented separately for bread and durum wheat.

In bread wheat, the main effect of plant parts on $F_{v} / F_{m}$ was not significant, however, the main effect of desiccation duration (time) and interaction effect between plant parts and time were significant. This suggests that $F_{v} / F_{m}$ in general remained nearly the same across plant parts and the effect of desiccation duration differed across plant parts. Analysis also revealed that $\mathrm{F}_{\mathrm{m}}$ differed significantly across plant parts and the effect of desiccation duration was also significant. There was the significant interaction between plant parts and desiccation duration for variable $F_{m}$. Similar observations were recorded for $F_{v}$ except that insignificant differences between plant parts were reported for this parameter. The main effects of plant parts and desiccation duration as well as interaction effects on $\mathrm{F}_{0}$ were also reported highly significant (Table 1).

In durum wheat, the effects of plant parts, desiccation duration, and interaction effects were significant for $\mathrm{F}_{\mathrm{v}} / \mathrm{F}_{\mathrm{m}}$ and $\mathrm{F}_{\mathrm{m}}$. Though the effects of plant parts and desiccation duration were significant, interaction effects of these two parameters were not significant for both $\mathrm{F}_{\mathrm{v}}$ and $\mathrm{F}_{0}$.

$\mathbf{F}_{\mathrm{v}} / \mathbf{F}_{\mathrm{m}}$ : In bread wheat, $\mathrm{F}_{\mathrm{v}} / \mathrm{F}_{\mathrm{m}}$ decreased progressively over the $4 \mathrm{~h}$ of desiccation in spike and leaf, but was almost constant in stem (Fig. 1). Before desiccation, the leaf had higher $F_{v} / F_{m}(0.81)$ relative to spike $(0.77)$ and stem (0.72). After $4-h$ desiccation, $F_{v} / F_{m}$ decreased rapidly in leaf (0.30) and spike (0.40) relative to stem (0.66; Fig. 1). In durum wheat, $F_{\mathrm{v}} / \mathrm{F}_{\mathrm{m}}$ decreased progressively over the $4 \mathrm{~h}$ of desiccation in spike, but the rate of decline was relatively constant in leaf and stem (Fig. 1). Before desiccation, $\mathrm{F}_{\mathrm{v}} / \mathrm{F}_{\mathrm{m}}$ did not differ significantly across plant parts [leaf (0.81), spike (0.77), and stem (0.72)]. After 4-h desiccation, there was marginal decrease of $F_{v} / F_{m}$ in stem (0.76), leaf (0.67), and spike (0.62; Fig. 1) in durum wheat.

$\mathbf{F}_{\mathbf{0}}$ : In bread wheat, there was a progressive increase in $\mathrm{F}_{0}$ during the 4-h desiccation across all three tissues which was in contrast to $F_{v} / F_{m}$ (Fig. 1). Before desiccation, $F_{0}$ was the least in leaf (64.3), followed by stem (83.8) and spike (94.9). After 4-h desiccation treatment, $\mathrm{F}_{0}$ increased almost by three folds in spike (295.2), leaf (270.4), and stem (227.7; Fig. 1). In durum wheat, $F_{0}$ increased progressively over the $4 \mathrm{~h}$ of desiccation across all three tissues (Fig. 1). Before desiccation, the lowest level of $\mathrm{F}_{0}$ was observed in leaf (69.4) in comparison to spike (93.5) and stem (105.2). After 4-h desiccation, $\mathrm{F}_{0}$ increased by almost three folds in spike (250.1) and by two folds in both leaf (223.3) and stem (210.7; Fig. 1).

$\mathbf{F}_{\mathbf{m}}$ and $\mathbf{F}_{\mathbf{v}}$ : In contrast to $\mathrm{F}_{\mathrm{v}} / \mathrm{F}_{\mathrm{m}}$ and $\mathrm{F}_{0}$, it was observed that $F_{m}$ and $F_{v}$ remained nearly constant during the first $2 \mathrm{~h}$ of desiccation and then started rising sharply. Increasing trend in both $F_{m}$ and $F_{v}$ was observed only after $3 \mathrm{~h}$ of desiccation in leaf and stem in bread and durum wheat. $\mathrm{F}_{\mathrm{v}}$ remained almost same throughout the desiccation period in spike, but slightly decreased in leaf and increased in stem at later stages (Fig. 1), which indicated different responses in plant parts of bread and durum wheat. 
Table 1. ANOVA results for the effects of organ, time, and their interactions on maximum quantum efficiency $\left(\mathrm{F}_{\mathrm{v}} / \mathrm{F}_{\mathrm{m}}\right)$, maximum fluorescence $\left(\mathrm{F}_{\mathrm{m}}\right)$, variable fluorescence $\left(\mathrm{F}_{\mathrm{v}}\right)$, and initial fluorescence $\left(\mathrm{F}_{0}\right)$ in bread and durum wheat.

\begin{tabular}{|c|c|c|c|c|c|}
\hline & Source & $D F$ & Mean square & $F$ value & $\operatorname{Pr}>F(\mathrm{G}-\mathrm{G})$ \\
\hline \multicolumn{6}{|c|}{ Bread wheat } \\
\hline \multirow[t]{5}{*}{$\mathrm{F}_{\mathrm{v}} / \mathrm{F}_{\mathrm{m}}$} & Plant parts & 2 & 0.0355 & 1.10 & 0.3630 \\
\hline & Time & 4 & 0.2220 & 37.64 & $<0.0001$ \\
\hline & Time $\times$ Plant parts & 8 & 0.0547 & 9.28 & $<0.0001$ \\
\hline & Error (Plant parts) & 12 & 0.0321 & & \\
\hline & Error (Time) & 48 & 0.0059 & & \\
\hline \multirow[t]{5}{*}{$\mathrm{F}_{\mathrm{m}}$} & Plant parts & 2 & $77,067.1402$ & 4.74 & 0.0303 \\
\hline & Time & 4 & $106,634.8321$ & 42.52 & $<0.0001$ \\
\hline & Time $\times$ Plant parts & 8 & $24,299.0984$ & 9.69 & 0.0001 \\
\hline & Error (Plant parts) & 12 & 0.0321 & & \\
\hline & Error (Time) & 48 & 0.0059 & & \\
\hline \multirow[t]{5}{*}{$\mathrm{F}_{\mathrm{v}}$} & Plant parts & 2 & $45,904.1073$ & 2.72 & 0.1058 \\
\hline & Time & 4 & $15,198.1264$ & 7.11 & 0.0020 \\
\hline & Time $\times$ Plant parts & 8 & $33,925.9074$ & 15.87 & $<0.0001$ \\
\hline & Error (Plant parts) & 12 & $16,852.3375$ & & \\
\hline & Error (Time) & 48 & $2,137.4271$ & & \\
\hline \multirow[t]{5}{*}{$\mathrm{F}_{0}$} & Plant Parts & 2 & $7,033.7858$ & 13.9 & 0.0008 \\
\hline & Time & 4 & $78,019.9258$ & 105.7 & $<0.0001$ \\
\hline & Time $\times$ Plant parts & 8 & $3,145.2547$ & 4.3 & 0.0028 \\
\hline & Error (Plant parts) & 12 & 506.8535 & & \\
\hline & Error (Time) & 48 & 738.5052 & & \\
\hline \multicolumn{6}{|c|}{ Durum wheat } \\
\hline \multirow[t]{5}{*}{$\mathrm{F}_{\mathrm{v}} / \mathrm{F}_{\mathrm{m}}$} & Plant parts & 2 & 0.0297 & 4.28 & 0.0396 \\
\hline & Time & 4 & 0.0178 & 4.90 & 0.0063 \\
\hline & Time $\times$ Plant parts & 8 & 0.0086 & 2.38 & 0.0517 \\
\hline & Error (Plant parts) & 12 & 0.0069 & & \\
\hline & Error (Time) & 48 & 0.0036 & & \\
\hline \multirow[t]{5}{*}{$\mathrm{F}_{\mathrm{m}}$} & Plant parts & 2 & $85,859.9930$ & 7.60 & 0.0074 \\
\hline & Time & 4 & $359,846.6020$ & 42.46 & $<0.0001$ \\
\hline & Time $\times$ Plant parts & 8 & $15,048.0160$ & 1.78 & 0.1822 \\
\hline & Error (Plant parts) & 12 & $11,291.2849$ & & \\
\hline & Error (Time) & 48 & $8,474.2640$ & & \\
\hline \multirow[t]{5}{*}{$\mathrm{F}_{\mathrm{v}}$} & Plant parts & 2 & $75,447.6380$ & 5.50 & 0.0201 \\
\hline & Time & 4 & $144,867.4588$ & 18.88 & $<0.0001$ \\
\hline & Time $\times$ Plant parts & 8 & $19,140.6423$ & 2.49 & 0.0812 \\
\hline & Error (Plant parts) & 12 & $13,710.2020$ & & \\
\hline & Error (Time) & 48 & $7,671.7025$ & & \\
\hline \multirow[t]{5}{*}{$\mathrm{F}_{0}$} & Plant parts & 2 & $7,869.2749$ & 7.19 & 0.0089 \\
\hline & Time & 4 & $48,531.5205$ & 40.47 & $<0.0001$ \\
\hline & Time $\times$ Plant parts & 8 & $1,119.8014$ & 0.93 & 0.4589 \\
\hline & Error (Plant parts) & 12 & $1,095.0526$ & & \\
\hline & Error (Time) & 48 & $1,199.1156$ & & \\
\hline
\end{tabular}

ChlF in bread wheat $v s$. durum wheat: $F_{v} / F_{m}$ differences between bread and durum wheat species were observed to be significant only during the later stage of desiccation, though the trend over time indicated superiority of durum over bread wheat (Figs. 1, 2). The $F_{\mathrm{v}} / \mathrm{F}_{\mathrm{m}}$ displayed significant differences in leaf tissue of bread wheat in comparison to durum wheat during $3^{\text {rd }}$ and $4^{\text {th }}$ hour of desiccation.

As similar to $F_{v} / F_{m}$, differences in $F_{0}$ between bread and durum wheat were observed to be significant only 


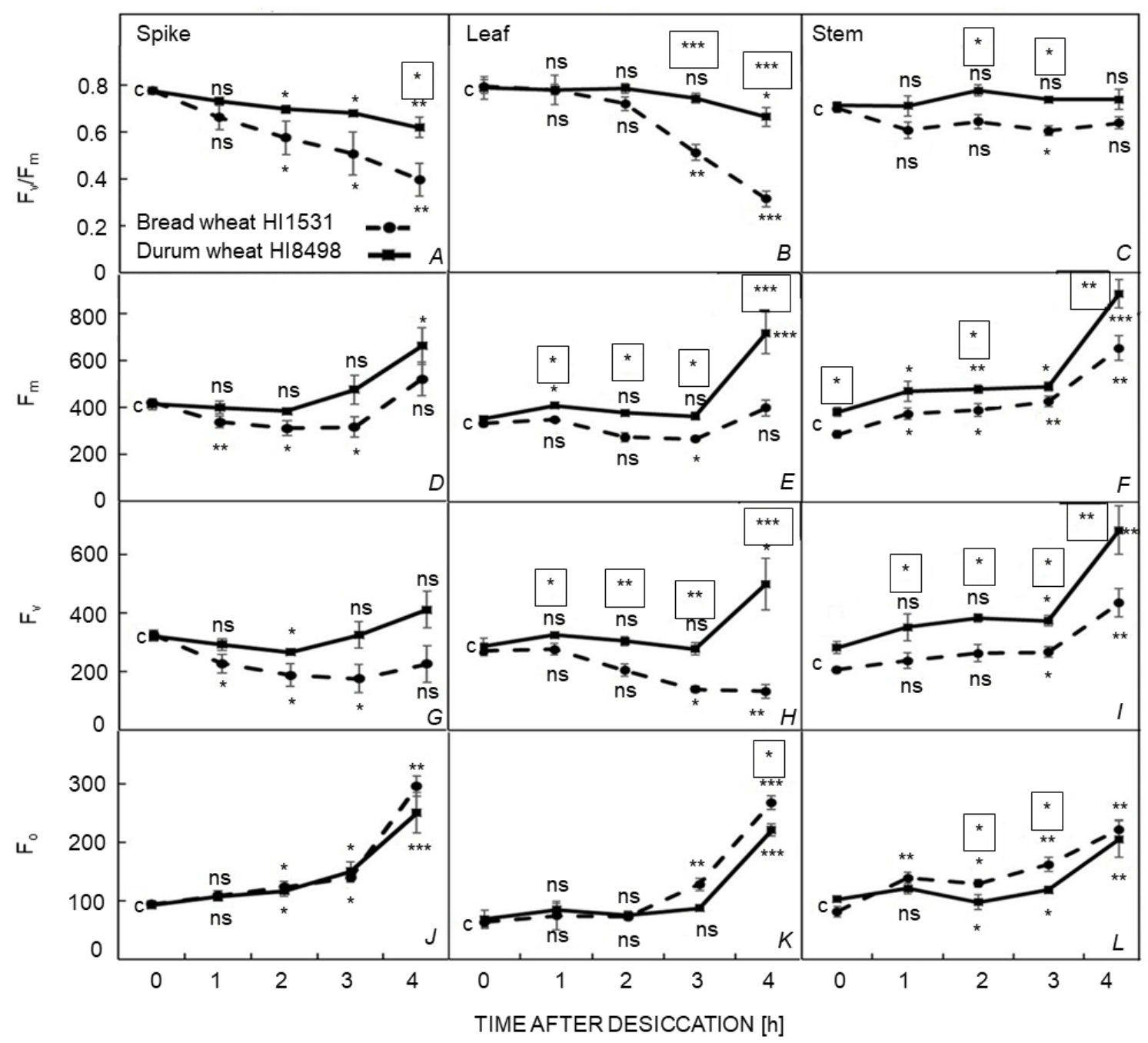

Fig. 1. Changes in maximum quantum efficiency $\left(\mathrm{F}_{\mathrm{v}} / \mathrm{F}_{\mathrm{m}}\right)$, maximum fluorescence $\left(\mathrm{F}_{\mathrm{m}}\right)$, variable fluorescence $\left(\mathrm{F}_{\mathrm{v}}\right)$, and initial fluorescence $\left(\mathrm{F}_{0}\right)$ in the spike, leaf, and stem tissues of bread (HI1531) and durum wheat (HI8498) over the $4 \mathrm{~h}$ of desiccation. Within a given tissue, and between bread and durum wheat (in the boxes), significant differences between time of treatment is indicated with asterisks, where $\mathrm{C}$ - reference, ns - nonsignificant, ${ }^{*}-P<0.05,{ }^{* *}-P<0.01$, and ${ }^{* * *}-P<0.001$. Data are presented as the mean of five replicates $\pm \mathrm{SE}$.

during the later stages of desiccation, particularly in spike and stem. There was a sharp increase in $\mathrm{F}_{0}$ after $3 \mathrm{~h}$ of desiccation both in spike and leaf. The observed trend in $\mathrm{F}_{0}$ over the duration of desiccation indicated superiority of durum wheat over bread wheat. In leaf tissue, significant differences in $\mathrm{F}_{0}$ was observed during $3^{\text {rd }}$ and $4^{\text {th }} \mathrm{h}$ of desiccation (Figs. 1, 2).

There was no significant difference detected in $\mathrm{F}_{\mathrm{m}}$ or $\mathrm{F}_{\mathrm{v}}$ between bread and durum wheat in spike. However, significant genotypic differences were observed at the later stages in leaves and stem.

\section{Discussion}

The successful implementation of a physiological trait in crop improvement programmes would be based on a careful selection of appropriate tool to measure physiological changes induced by stress. ChlF imaging is a costeffective and powerful analytical tool to elucidate relative photosynthetic efficiency of crop plants. In contrast to instruments routinely used for point measurements, ChlF imaging system provides additional advantage of spanning many points in a plant organ for ChlF signals (Rousseau et al. 2015). Both conventional instruments and imaging systems have been used for assessing plant stress responses often with focus on leaf photosynthetic efficiency (Nesterenko et al. 2015, Kalaji et al. 2017, Eisvand et al. 2018). To the best of our knowledge there are rare attempts made to investigate PSII photosynthetic efficiency of spike and a known example is for assessing influence of diseases (Bauriegel et al. 2011), but not for responses to stresses such as desiccation. Recently, improvement of photosynthesis in spike is being projected as a new opportunity to enhance productivity of wheat (Jia et al. 2015). Hence, we designed our experiment to assess efficiency of Chl imaging technique to differentiate spike PSII. One of the breeding techniques, proposed to increase yield potential and to improve adaptation to increased 


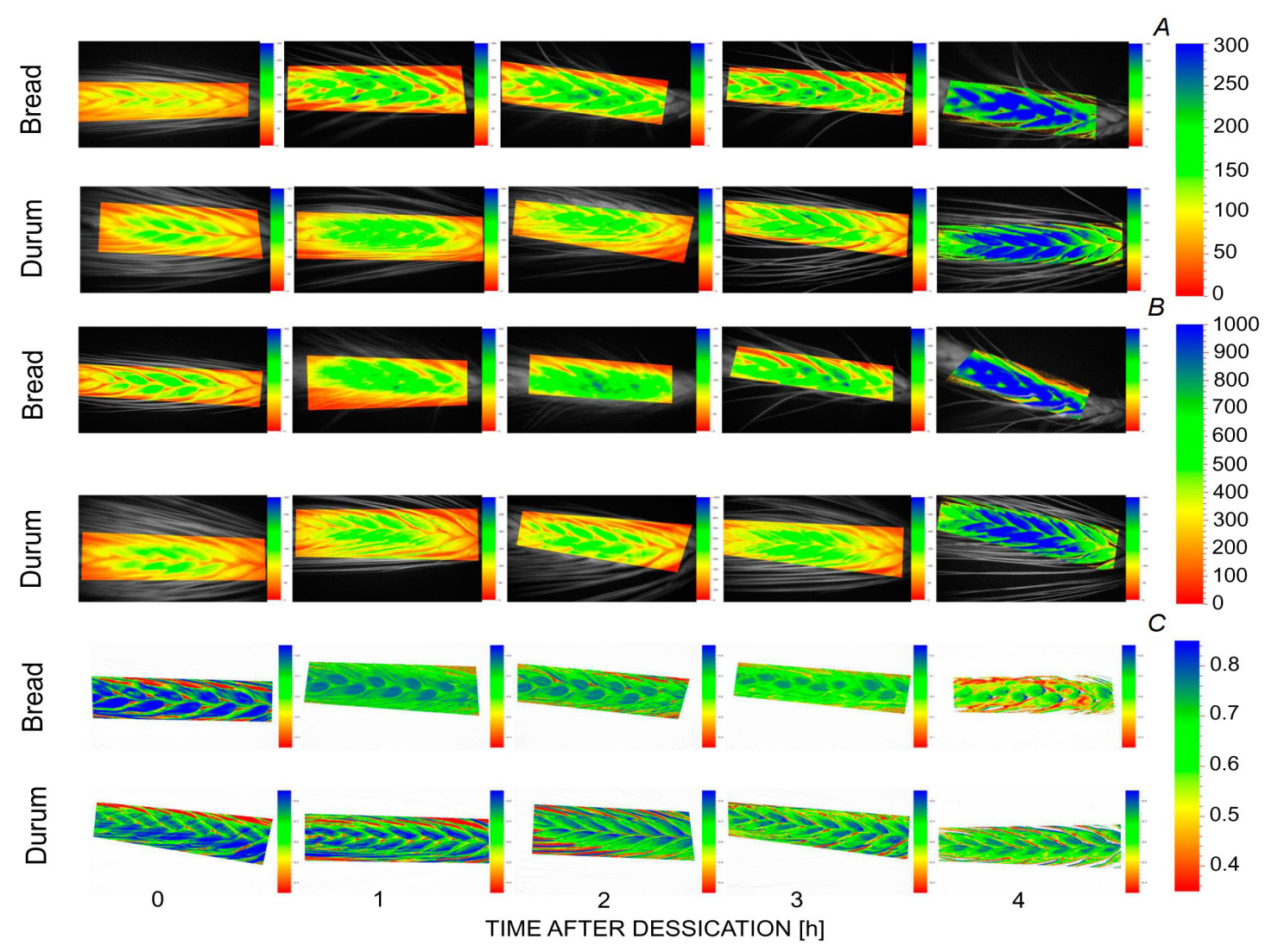

Fig. 2. Chlorophyll fluorescence images of initial fluorescence $\left(\mathrm{F}_{0}\right)(A)$, maximum fluorescence $\left(\mathrm{F}_{\mathrm{m}}\right)(B)$, and maximum photochemical efficiency of PSII $\left(\mathrm{F}_{\mathrm{v}} / \mathrm{F}_{\mathrm{m}}\right)(C)$ in spikes of bread (HI1531) and durum wheat (HI8498) over the $4 \mathrm{~h}$ of desiccation. Pixel value images of $\mathrm{F}_{\mathrm{v}} / \mathrm{F}_{\mathrm{m}}$ were displayed as a false colour code ranging from red, through green and yellow to blue. The scale ranged from 0 (red) to 300 (blue) for $F_{0}$; from red $(0)$ to blue $(1,000)$ for $F_{m}$, and from 0.35 (red) to 0.85 (blue) for $F_{v} / F_{m}$.

occurrences of abiotic stresses (such as drought and heat), is to select for higher ear photosynthesis (Tambussi et al. 2007, Araus et al. 2008) and to develop trait assessment methods (Sanchez-Bragado et al. 2016).

We chose bread wheat and durum wheat as they are conventionally differentiated for their adaptation to harsh stresses such as terminal drought stress. We hypothesised that photosynthetic efficiency of PSII of durum must be superior to that of bread wheat and that ChlF imaging technique can efficiently differentiate these two wheat species. The basis for our approach was that $F_{0}$ and $F_{v} / F_{m}$ are well-known indicators of photosynthetic efficiency and photoinhibition during desiccation (Brandes et al. 2006). It was anticipated that significant genetic variation in $\mathrm{F}_{0}$ or/and $\mathrm{F}_{\mathrm{m}}$ during desiccation could translate into detectable differences in maximum quantum efficiency of PSII $\left(\mathrm{F}_{\mathrm{v}} / \mathrm{F}_{\mathrm{m}}\right)$. An increase in $\mathrm{F}_{0}$ and decrease in $\mathrm{F}_{\mathrm{v}} / \mathrm{F}_{\mathrm{m}}$ indicates photoinhibition and downregulation of photosynthesis, which can be visualized and quantified through imaging system. Thus, despite reports on a number of parameters to interpret ChlF transient (Kalaji et al. 2017) and also demonstrated relevance to stress responses of plants (Maxwell and Johnson 2000), we focused on limited parameters such as $F_{0}, F_{m}$, and $F_{v} / F_{m}$. Further, these parameters offer greater feasibility for employing techniques for medium to high throughput screening of wheat genotypes for responses to desiccation or drought. We also simultaneously measured $\mathrm{ChlF}$ variables in leaf and stem for visualizing deviations, if any, across the plant parts in trends of ChlF parameters during desiccation.

We chose grain-filling period for differentiating two different species of wheat in terms of photosynthetic efficiency of PSII. During grain filling, the combination of high irradiance and water stress and/or high temperatures may have a synergistic effect on the development of photoinhibition (Powles 1984, Bolhar-Nordenkampf et al. 1991). It has been reported that fluorescence indicators in wheat exhibit intrinsic variation after heading (Pastore et al. 1989) or flowering (Flagella et al. 1994), which suggests a relationship with plant senescence. However, in our experiment, precautionary measures were taken to avoid effect of phenology on ChlF parameters by sampling spikes from plants of a similar phenological stage.

Our study proposed ChlF imaging system as an efficient tool to assess genetic variation in spike PSII photosynthetic efficiency of wheat subjected to desiccation. This derives support from the significant inter-species difference in $\mathrm{F}_{\mathrm{v}} / \mathrm{F}_{\mathrm{m}}$, an indicator of maximum efficiency of PSII (Maxwell and Johnson 2000), observed in our experiment, and these differences were clearly exhibited after 3-4 h of desiccation. The trend observed in spike PSII sensitivity to desiccation was almost the same as observed in leaf. There 
have been several reports of using ChlF kinetics of leaves to explain stress tolerance in plants (Di Marco et al. 1988, Ali-Dib et al. 1994, Nogués et al. 1994, Guo et al. 2016, Osipova et al. 2019). In one of the earlier durum wheat study, the photochemical capacity of PSII was measured by means of $\mathrm{F}_{\mathrm{v}} / \mathrm{F}_{\mathrm{m}}$ in a set of 144 genotypes (Araus et al. 1998). In this experiment, plants grown under soil moisture stress environments were found to have significantly lesser values of ChlF parameters including $\mathrm{F}_{\mathrm{v}} / \mathrm{F}_{\mathrm{m}}$ when compared to those in irrigated environments. However, there was no significant genotype effect for $F_{v} / F_{m}$. The decrease in $F_{v} / F_{m}$ and increase in $\mathrm{F}_{0}$ under water-deficient environment reported by Araus et al. (1998) aligns with our results. They did not find any genotypic effect on $\mathrm{F}_{\mathrm{v}} / \mathrm{F}_{\mathrm{m}}$ in their experiment, which had only durum genotypes, but we observed the genotypic effect when durum was compared to bread wheat.

A decline in $\mathrm{F}_{\mathrm{v}} / \mathrm{F}_{\mathrm{m}}$ is a good indicator of photoinhibitory impairment when plants are subjected to a wide range of environmental stresses, including drought and heat (Araus and Hogan 1994, Angelopoulos et al. 1996, Yang et al. 1996). While interpreting $\mathrm{F}_{\mathrm{v}} / \mathrm{F}_{\mathrm{m}}$, it is important to distinguish increase in $F_{0}$ from decrease in $F_{v}$. An increase in $\mathrm{F}_{0}$, the fluorescence emission when all reaction centers are open and the photochemical quenching is minimal, is characteristic of destruction of PSII reaction centers, or the impairment of transfer of excitation energy from antenna to the reaction centers. In the present experiment, the $\mathrm{F}_{0}$ increased by more than two folds after $4 \mathrm{~h}$ of desiccation of spike suggesting that there was negative impact on PSII reaction centres in both the species but the level of damage was lesser in durum than that in bread wheat as evident from ChlF images (Fig. 2). A decline in $F_{v}$ (caused by a decrease in $\mathrm{F}_{\mathrm{m}}$ ) may indicate an increase in nonphotochemical quenching (Bolhar-Nordenkampf et al. 1991). However, in the present study, there was gradual increase in $F_{v}$, particularly in durum wheat indicating that the decrease in $F_{v} / F_{m}$ was not necessarily due to nonphotochemical quenching, which would have become more clear with OJIP test. This test requires more time for each measurement and hence is not feasible for efficient screening of large number of genotypes.

In available literature, there is demonstrative evidence that bread wheat and durum wheat have inherent differences in their desiccation tolerance. Furthermore, spike, flag leaf, and stem tissues of durum wheat are also considered to have different mechanisms to maintain their photosynthetic capacity under desiccation (Inoue et al. 2004). Recent reports showed the presence of a $\mathrm{C}_{4}$ photosynthetic pathway in developing bread wheat grain that is absent in leaves and stem (Rangan et al. 2016). The existence of different photosynthetic mechanisms in these organs may be associated with the differential response of $\mathrm{F}_{\mathrm{v}} / \mathrm{F}_{\mathrm{m}}$ and $\mathrm{F}_{0}$ in different photosynthetic organs. On the contrary, Tambussi et al. (2005) and Li et al. (2017) demonstrated that durum wheat spike is not associated with any $\mathrm{C}_{4}$ or CAM photosynthetic pathway.

The present investigation showed higher stability of PSII photosynthetic efficiency in durum wheat, compared to bread wheat. The lower $\mathrm{F}_{0}$ and higher $\mathrm{F}_{\mathrm{v}} / \mathrm{F}_{\mathrm{m}}$ across all plant parts of durum wheat, in comparison to bread wheat, implied that PSII of durum wheat has greater capacity to tolerate desiccation-induced damage. Better adaptability of durum wheat towards desiccation may be due to its evolution in the Mediterranean basin, where terminal drought prevails during the late spring (Royo et al. 1995, Acevedo et al. 1999), in comparison to bread wheat which is grown mainly in temperate environments. In addition, genotypes chosen for the studies were tested and developed for central India, where grain-growth phase for wheat is hot and dry. Further, durum wheat is closer to wild emmer wheat and rich allelic repertoire of emmer wheat was extensively utilized for drought tolerance breeding in durum wheat (Peleg et al. 2007). Nevertheless, photosynthetic performance of leaf was more affected by desiccation than that of spike and stem. Xu and Ishii (1990) and Tambussi et al. (2005) observed that osmotic adjustment and xeromorphic traits of spike provide better protection against water stress. In addition to xeromorphic traits and osmotic adjustment, vertical heterogeneity in leaf sclerophyllous characteristics has been reported in wheat (Araus et al. 1986), which could generate xeromorphic conditions in upper levels of the plant and consequently impart tolerance to desiccation, particularly, in spikes and awns.

We summarize that despite relatively lesser tissue moisture content, spike PSII of durum wheat was found to be more tolerant to desiccation when compared to bread wheat. PSII sensitivity of spike in wheat plant can be as a good indicator as that of leaf, hence it can be useful in improving photosynthetic capacity of wheat spike under harsher environments. This investigation proved that ChlF imaging system can be extremely useful for studies on genetic variation in spike PSII sensitivity to tissue desiccation, which often results from soil moisture deficit. This technique can facilitate medium to high throughput screening of wheat genotypes for drought tolerance with focus on spike photosynthetic capacity.

\section{References}

Abbad H., Jaafari S.E., Bort J., Arraus J.L.: Comparison of flag leaf and ear photosynthesis with biomass and grain yield of durum wheat under various water conditions and genotypes. Agronomie 24: 19-28, 2004.

Acevedo E.H., Silva P.C., Silva H.R., Solar B.R.: Wheat production in Mediterranean environments. - In: Satorre E.H., Slafer G.A. (ed.): Wheat: Ecology and Physiology of Yield Determination. Pp. 295-323. Food Products Press, New York 1999.

Aggarwal P.K., Singh A.K., Chaturvedi G.S., Sinha S.K.: Performance of wheat and triticale cultivars in a variable soil-water environment. II. Evapotranspiration, water use efficiency, harvest index and grain yield. - Field Crop. Res. 13: 301-315, 1986.

Al-Ghzawi A.L.A., Khalaf Y.B., Al-Ajlouni Z.I. et al.: The effect of supplemental irrigation on canopy temperature depression, chlorophyll content, and water use efficiency in three wheat (Triticum aestivum L. and T. durum Desf.) varieties grown in dry regions of Jordan. - Agriculture 8: 67, 2018.

Ali-Dib T., Monneveux P., Acevedo E., Nachit M.M.: Evaluation of proline analysis and chlorophyll fluorescence quenching 
measurements as drought tolerance indicators in durum wheat (Triticum turgidum L. var. durum). - Euphytica 79: 65-73, 1994.

Angelopoulos K., Dichio B., Xiloyannis C.: Inhibition of photosynthesis in olive trees (Olea europaea L.) during water stress and rewatering. - J. Exp. Bot. 47: 1093-1100, 1996.

Araus J.L., Alegre L., Tapia L., Calafell R.: Relationship between leaf structure and gas exchange in wheat leaves at different insertion levels. - J. Exp. Bot. 37: 1323-1333, 1986.

Araus J.L., Amaro T., Voltas J. et al.: Chlorophyll fluorescence as a selection criterion for grain yield in durum wheat under Mediterranean conditions. - Field Crop. Res. 55: 209-223, 1998.

Araus J.L., Brown H.R., Febrero A. et al.: Ear photosynthesis, carbon isotope discrimination and the contribution of respiratory $\mathrm{CO}_{2}$ to differences in grain mass in durum wheat. - Plant Cell Environ. 16: 383-392, 1993.

Araus J.L., Hogan K.P.: Comparative leaf structure and patterns of photoinhibition of the neotropical palms Scheelea zonensis and Socratea durissima growing in clearings and forest understory during the dry season in Panama. - Am. J. Bot. 81: 726-738, 1994.

Araus J.L., Slafer G.A., Royo C., Serret M.D.: Breeding for yield potential and stress adaptation in cereals. - Crit. Rev. Plant Sci. 27: 377-412, 2008.

Bauriegel E., Giebel A., Herppich W.B.: Hyperspectral and chlorophyll fluorescence imaging to analyse the impact of Fusarium culmorum on the photosynthetic integrity of infected wheat ears. - Sensors-Basel 11: 3765-3779, 2011.

Bolhar-Nordenkampf H.R., Hofer M., Lechner E.G.: Analysis of light-induced reduction of the photochemical capacity in fieldgrown plants. Evidence for photoinhibition. - Photosynth. Res. 27: 31-39, 1991.

Brandes E., Kodama N., Whittaker K. et al.: Short term variation in the isotopic composition of organic matter allocated from the leaves to the stem of Pinus sylvestris: Effects of photosynthetic and postphotosynthetic carbon isotope fractionation. - Glob. Change Biol. 12: 1922-1939, 2006.

Calderini D.F., Reynolds M.P., Slafer G.A.: Source-sink effects on grain weight of bread wheat, durum wheat, and triticale at different locations. - Aust. J. Agr. Res. 57: 227-233, 2006.

Di Marco G., Massacci A., Gabrielli R.: Drought effects on photosynthesis and fluorescence in hard wheat cultivars grown in the field. - Physiol. Plantarum 74: 385-390, 1988.

Eisvand H.R., Kamaei H., Nazarian F.: Chlorophyll fluorescence, yield and yield components of bread wheat affected by phosphate bio-fertilizer, zinc and boron under late-season heat stress. - Photosynthetica 56: 1287-1296, 2018.

Evans L.T., Wardlaw I.F., Fischer R.A.: Wheat. - In: Evans L.T. (ed.): Crop Physiology: Some Case Histories. Pp. 101-150, Cambridge University Press, Cambridge 1975.

Falk S., Maxwell D.P., Laudenbach D.E., Huner N.P.A.: Photosynthetic adjustment to temperature. - In: Baker N.R. (ed.): Photosynthesis and the Environment. Pp. 367-385. Kluwer Academic Publishers, Dordrecht-Boston-London 1996.

Flagella Z., Pastore D., Campanile R.G. et al.: Photochemical quenching of chlorophyll fluorescence and drought tolerance in different durum wheat (Triticum durum) cultivars. - J. Agr. Sci.-Cambridge 122: 183-192, 1994.

Giardi M.T., Cona A., Geiken B. et al:: Long-term drought stress induces structural and functional reorganization of photosystem II. - Planta 199: 118-125, 1996.

Goltsev V.N., Kalaji H.M., Paunov M. et al.: Variable chlorophyll fluorescence and its use for assessing physiological condition of plant photosynthetic apparatus. - Russ. J. Plant Physl+63: 869-893, 2016.
Guidi L., Calatayud A.: Non-invasive tools to estimate stressinduced changes in photosynthetic performance in plants inhabiting Mediterranean areas. - Environ. Exp. Bot. 103: 42-52, 2014.

Guo J., Xu W., Yu X. et al.: Cuticular wax accumulation is associated with drought tolerance in wheat near-isogenic lines. - Front. Plant Sci. 7: 1809, 2016.

Hochman Z., Holzworth D., Hunt J.R.: Potential to improve on-farm wheat yield and WUE in Australia. - Crop Pasture Sci. 60: 708-716, 2009.

Inoue T., Inanaga S., Sugimoto Y. et al.: Effect of drought on ear and flag leaf photosynthesis of two wheat cultivars differing in drought resistance. - Photosynthetica 42: 559-565, 2004.

Jia S., Lv J., Jiang S. et al.: Response of wheat ear photosynthesis and photosynthate carbon distribution to water deficit. Photosynthetica 53: 95-109, 2015.

Josephides C.M.: Analysis of adaptation of barley, triticale, durum and bread wheat under Mediterranean conditions. Euphytica 65: 1-8, 1992.

Kalaji H.M., Schansker G., Brestič M. et al.: Frenquently asked questions about chlorophyll fluorescence, the sequel. Photosynth. Res. 132: 13-66, 2017.

Lazár D.: Parameters of photosynthetic energy partitioning. J. Plant Physiol. 175: 131-147, 2015.

Li Y.P., Li Y.Y., Li D.Y. et al.: Photosynthetic response of tetraploid and hexaploid wheat to water stress. - Photosynthetica 55: 454-466, 2017.

Lichtenthaler H.K., Buschmann C., Knapp M.: How to correctly determine the different chlorophyll fluorescence parameters and the chlorophyll fluorescence decrease ratio RFd of leaves with the PAM fluorometer. - Photosynthetica 43: 379-393, 2005.

López-Castañeda C., Richards R.A.: Variation in temperate cereals in rainfed environments. I. Grain yield, biomass and agronomic characteristics. - Field Crop. Res. 37: 51-62, 1994.

Lu C., Zhang J.: Effects of water stress on photosynthesis, chlorophyll fluorescence and photoinhibition in wheat plants. - Funct. Plant Biol. 25: 883-892, 1998.

Marti J., Slafer G.A.: Bread and durum wheat yields under a wide range of environmental conditions. - Field Crop. Res. 156: 258-271, 2014.

Maxwell K., Johnson G.N.: Chlorophyll fluorescence a practical guide. - J. Exp. Bot. 51: 659-668, 2000.

Maydup M.L., Antonietta M., Guiamet J.J., Tambussi E.A.: The contribution of green parts of the ear to grain filling in old and modern cultivars of bread wheat (Triticum aestivum L.): Evidence for genetic gains over the past century. - Field Crop. Res. 134: 208-215, 2012.

Monneveux P., Jing R., Misra S.: Phenotyping for drought adaptation in wheat using physiological traits. - Front. Physiol. 3: 429, 2012.

Nedbal L., Soukupová J., Kaftan D. et al.: Kinetic imaging of chlorophyll fluorescence using modulated light. - Photosynth. Res. 66: 3-12, 2000.

Nesterenko T.V., Shikhov V.N., Tikhomirov A.A.: Effect of light intensity on the age dependence of nonphotochemical fluorescence quenching in wheat leaf. - Photosynthetica 53: 617-620, 2015.

Nogués S., Alegre L., Araus J.L. et al:: Chlorophyll fluorescence and photosynthetic gas exchange as rapid screening methods for tolerance to water-stress in barley. - Photosynthetica 30: 465-474, 1994.

Osipova S.V., Permyakov A.V., Permyakova M.D., Rudikovskaya E.G.: Tolerance of the photosynthetic apparatus in recombinant lines of wheat adapting to water stress of varying intensity. Photosynthetica 57: 160-169, 2019. 
Palumbo M., Boggini G.: Comparison of durum wheat, bread wheat and barley in a Mediterranean environment. - Cereal Res. Commun. 113: 120, 1994.

Pastore D., Flagella Z., Rascio A. et al.: Field studies on chlorophyll fluorescence as drought tolerance test in Triticum durum Desf. genotypes. - J. Genet. Breeding 43: 45-51, 1989.

Peleg Z., Fahima T., Saranga Y.: Drought resistance in wild emmer wheat: physiology, ecology, and genetics. - Israel J. Plant Sci. 55: 289-296, 2007.

Powles S.B.: Photoinhibition of photosynthesis induced by visible light. - Ann. Rev. Plant Physio. 35: 15-44, 1984.

Rangan P., Furtado A., Henry R.J.: New evidence for grain specific $\mathrm{C}_{4}$ photosynthesis in wheat. - Sci. Rep.-UK 6: 31721 , 2016.

Reynolds M.P., Mujeeb-Kazi A., Sawkins M.: Prospects for utilising plant-adaptive mechanisms to improve wheat and other crops in drought- and salinity-prone environments. Ann. Appl. Biol. 146: 239-259, 2005.

Reynolds M.P., Quilligan E., Aggarwal P.K. et. al.: An integrated approach to maintaining cereal productivity under climate change. - Glob. Food Secur. 8: 9-18, 2016.

Rousseau C., Hunault G., Gaillard S. et al.: Phenoplant: A web resource for the exploration of large chlorophyll fluorescence image datasets. - Plant Methods 11: 24, 2015.

Royo C., Michelena A., Carrillo J.M. et al.: Spanish durum wheat breeding program. - In: Nachit M.M., Baum M., Porceddu E. et al. (ed.): SEWANA (South Europe, West Asia and North Africa) durum research network. Pp. 80-87. Proceedings of the SEWANA durum network workshop, ICARDA, Aleppo 1995.

Sanchez-Bragado R., Molero G., Reynolds M.P., Araus J.L.: Photosynthetic contribution of the ear to grain filling in wheat: A comparison of different methodologies for evaluation. J. Exp. Bot. 67: 2787-2798, 2016.

Sayed O.H.: Chlorophyll fluorescence as a tool in cereal crop research. - Photosynthetica 41: 321-330, 2003.

Simmons S.R.: Growth, development and physiology. In: Heyne E.G. (ed.): Wheat and Wheat Improvement. Pp. 77113. American Society of Agronomy Inc., Madison 1987.

Skotnica J., Matoušková M., Nauš J. et al.: Thermoluminescence and fluorescence study of changes in Photosystem II photochemistry in desiccating barley leaves. - Photosynth. Res. 65: 29-40, 2000.

Stirbet A., Lazár D., Kromdijk J., Govindjee: Chlorophyll a fluorescence induction: Can just a one-second measurement be used to quantify abiotic stress responses? - Photosynthetica 56: 86-104, 2018.

Tambussi E.A., Bort J., Guiamet J.J. et al.: The photosynthetic role of ears in $\mathrm{C}_{3}$ cereals: metabolism, water use efficiency and contribution to grain yield. - Crit. Rev. Plant Sci. 26: 1-16, 2007.

Tambussi E.A., Nogués S., Araus J.L.: Ear of durum wheat under water stress: water relations and photosynthetic metabolism. Planta 221: 446-458, 2005.

Terrile I.I., Miralles D.J., González F.G.: Fruiting efficiency in wheat (Triticum aestivum L): Trait response to different growing conditions and its relation to spike dry weight at anthesis and grain weight at harvest. - Field Crop. Res. 201: 86-96, 2017

Trethowan R.M., Singh R.P., Huerta-Espino J. et al.: Coleoptile length variation of near-isogenic Rht lines of modern CIMMYT bread and durum wheats. - Field Crop. Res. 70: 167-176, 2001.

Vaghar M., Ehsanzadeh P.: Comparative photosynthetic attributes of emmer and modern wheats in response to water and nitrogen supply. - Photosynthetica 56: 1224-1234, 2018.

Varshney R.K., Thudi M., Pandey M.K.: Accelerating genetic gains in legumes for the development of prosperous smallholder agriculture: integrating genomics, phenotyping, systems modelling and agronomy. - J. Exp. Bot. 69: 32933312, 2018.

Xu H.L., Ishii R.: Effects of water deficit on photosynthesis in wheat plants. V. Difference among plant parts in water relations. - Plant Prod. Sci. 59: 384-389, 1990.

Yang G.P., Rhodes D., Joly R.J.: Effects of high temperature on membrane stability and chlorophyll fluorescence in glycinebetaine-deficient and glycinebetaine-containing maize lines. - Aust. J. Plant Physiol. 23: 437-443, 1996.

Zadoks J.C., Chang T.T., Konzak C.F.: A decimal code for the growth stages of cereals. - Weed Res. 14: 415-421, 1974.

Zubaidi A., McDonald G.K., Hollamby G.J.: Shoot growth, root growth and grain yield of bread and durum wheat in South Australia. - Aust. J. Exp. Agr. 39: 709-720, 1999.

Živčák M., Brestič M., Balatová Z. et al.: Photosynthetic electron transport and specific photoprotective responses in wheat leaves under drought stress. - Photosynth. Res. 117: 529-546, 2013.

(C) The authors. This is an open access article distributed under the terms of the Creative Commons BY-NC-ND Licence. 